\title{
Wide Stopband Microstrip Bandpass Filter Based on a Compact Slotted Ground Structure
}

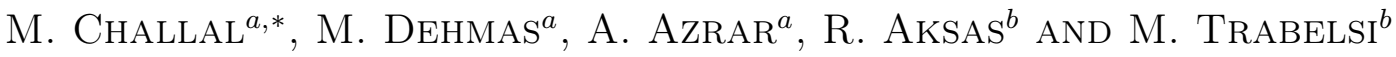 \\ ${ }^{a}$ University of Boumerdes, Institute of Electrical and Electronic Engineering, \\ Dept. of Electronics, Boumerdès, Algeria \\ ${ }^{b}$ National Polytechnic School, Dept. of Electronics, Algiers, Algeria
}

\begin{abstract}
A new concept for implementing a bandpass filter by employing a discontinuity in the feed microstrip line in the upper layer and modified dumbbell-shaped slots etched in the ground plane is proposed. The effect of the slot area on the bandpass filter performance is examined. The proposed bandpass filter showed wide stopband and low insertion loss. To further verify the new concept, the structure is implemented and the measurement results are found to be in good agreement with the simulation ones. The proposed structure can be used in various microwave circuits.
\end{abstract}

DOI: $10.12693 /$ APhysPolA.128.B-71

PACS: $84.30 . \mathrm{Vn}, 84.40 .-\mathrm{x}$

\section{Introduction}

Modern communication systems require miniaturized high performance bandpass filters (BPFs) containing high selectivity in the stopband and low insertion loss (IL) in the passband. These types of filters are presently used in communication application to allow a certain range of frequencies to pass through and attenuate a certain range of frequencies lying in some other specific ranges. Lately, there has been an increasing interest in microstrip BPFs design using slots etched in the ground plane, known as defected ground structure (DGS) [1-3]. Moreover, this technique of etching in the ground plane is as well applied to $\mathrm{RF} /$ microwave circuits to reduce the size and improve the performances $[4,5]$. A variety of DGS shapes for BPFs applications has been presented in literature [1-3]. Nevertheless, there is always a trade-off between the performance and the filter physical.

In this paper, we present a wide rejection band and compact microstrip BPF using a discontinuity in the feed microstrip line in the upper layer and two identical modified dumbbell-shaped DGS patterns. A parametric study is carried out to display the effect of slot area on the BPF performance. The proposed microstrip $\mathrm{BPF}$ is fabricated and measured using a vector network analyzer (VNA) and the results are compared with the simulation results. The proposed structure has compact size with good agreement between the measured and simulated responses.

\section{Design concept}

Figure 1 shows the proposed filter which is composed of a discontinuity in the $50 \Omega$ feed microstrip line in the

*corresponding author; e-mail: mchallal@umbb.dz upper layer and two identical modified dumbbell-shaped DGS patterns. The proposed BPF structure is printed on a dielectric substrate of an epoxy glass type with a relative permittivity of $\varepsilon_{r}=4.4$ and a thickness of $h=1.6 \mathrm{~mm}$. Dielectric and metallic losses, as well as the finite thickness of the metallic layers were taken into account during the design. The DGS based BPF dimensions $A, B, C, D, M, T, S$, and $w$ are considered to be $5.75,1.5,2.75,5.6,0.25,0.4,1.1$, and $3.06 \mathrm{~mm}$, respectively. The width of the feed microstrip line is calculated for the characteristic impedance of $50 \Omega$.

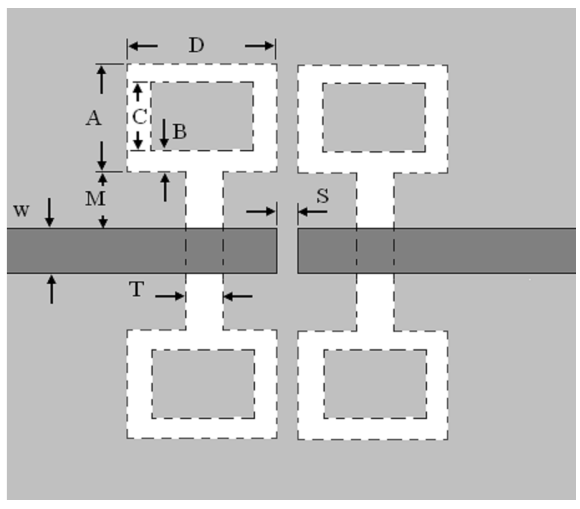

Fig. 1. The proposed microstrip BPF.

\section{Effect of the DGS dimensions and the separation distance $S$ on the BPF performance}

For the proposed DGS based BPF, the effect of the dimensions on the performance of the filter are studied, based on electromagnetic (EM) simulation results. The structure shown in Fig. 1 with $A=5.75 \mathrm{~mm}$, $B=1.5 \mathrm{~mm}, C=2.75 \mathrm{~mm}, D=5.6 \mathrm{~mm}, M=0.25 \mathrm{~mm}$, $T=0.4 \mathrm{~mm}$ and $S=1.1$ is used in this study.

Figure 2 shows the influence of the change in the length $D$ on the behaviour of $S_{21}$ and $S_{11}$ while the other pa- 
rameters of the structure are kept constant. It is noticed that the increase in this length leads to a shift towards the low frequencies. Concerning the return loss in the passband, it can be seen that its value is increased from $15 \mathrm{~dB}$ to $2 \mathrm{~dB}$.

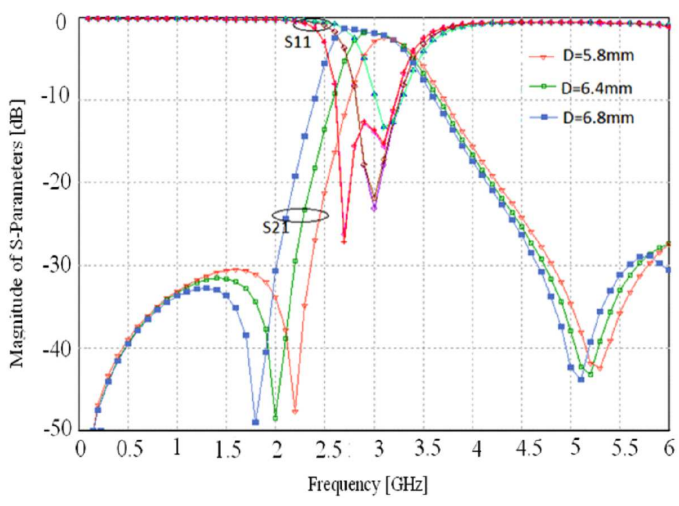

Fig. 2. Magnitude of $\mathrm{S}_{21}$ and $\mathrm{S}_{11}$ for different $D$.

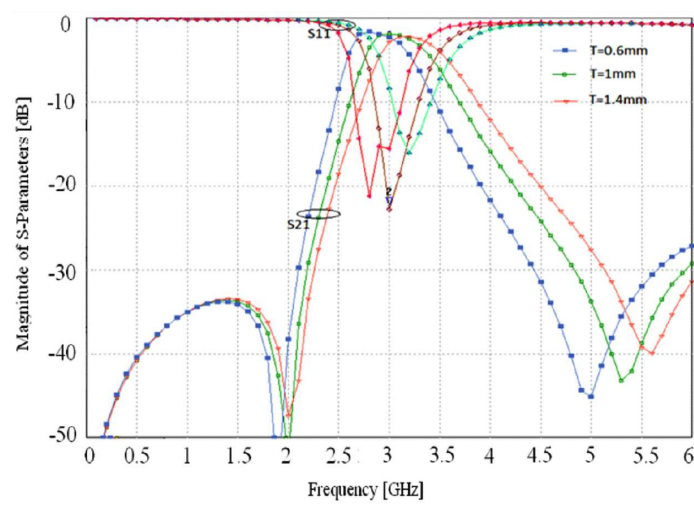

Fig. 3. Magnitude of $\mathrm{S}_{21}$ and $\mathrm{S}_{11}$ for different $T$.

Figure 3 shows the influence of the change in the length $T$ on the behavior of $S_{21}$ and $S_{11}$ while the other parameters of the structure are kept constant. It can be observed that the increase in this length leads to a shift towards the high frequencies.

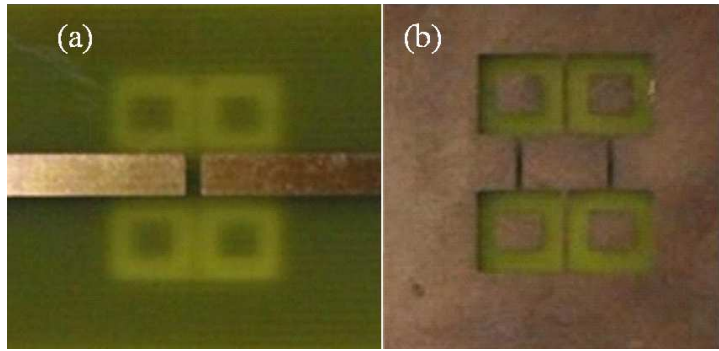

Fig. 4. Fabricated BPF: (a) top view and (b) bottom view.

For an experimental demonstration, the designed filter with fixed dimensions by EM simulation was fabricated on a dielectric substrate of an epoxy glass which has a relative dielectric constant of 4.4 , a thickness of $1.6 \mathrm{~mm}$, a dielectric loss of 0.0017 , and a metallic thickness of $35 \mu \mathrm{m}$. The top and bottom views of the filter are shown in Fig. 4a and b, respectively. The pair of $50 \Omega$ end-coupled microstrip lines is extended for the measurement purpose, while the actual size of the filter is only $12.3 \times 14.5 \mathrm{~mm}^{2}$ on the used substrate. Figure 5 shows the simulated and measured response of the BPF. These results show a $3 \mathrm{~dB}$ bandwidth is $0.52 \mathrm{GHz}$, representing a FBW of $18.57 \%$ at the center frequency of $2.8 \mathrm{GHz}$. The insertion loss is less than $0.4 \mathrm{~dB}$. The measured return loss performance is more than $20 \mathrm{~dB}$ rejection band is greater than $28 \mathrm{~dB}$ over a very broadband. The mismatch between measured and simulated results is mainly due to a misalignment between the top and bottom patterned circuits during the fabrication.

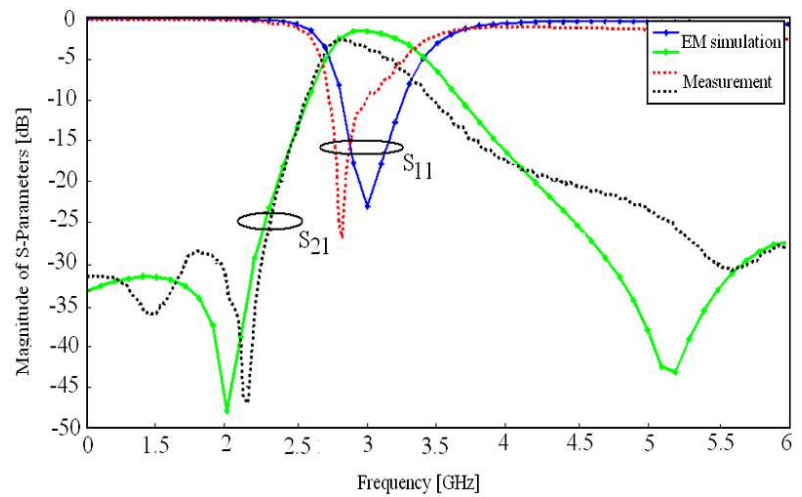

Fig. 5. Measured and simulated $S$-parameter responses for the proposed BPF.

\section{Conclusion}

In this paper, the design and implementation of a compact microstrip bandpass filter, with a wide reject band, using a discontinuity in the feed microstrip line in the upper layer and modified dumbbell-shaped slots etched in the ground plane has been presented. The proposed filter has been verified by comparing $S$-parameters from EM simulation and experimental results. The measured results are in good agreement with the simulation ones.

\section{References}

[1] J.S. Park, J.S. Yun, D. Ahn, IEEE Trans. Microw. Theory Tech. 50, 2037 (2002).

[2] F. Fangfang, Y. Zehong, Microwave Opt. Technol. Lett. 52, 17 (2010).

[3] H. Louazene, M. Boulakroune, M. Challal, in: Proc. IEEE Int. Symp. Networks, Computers and Communications, Tunisia, IEEE, Hammamet 2014, p. 1.

[4] M. Challal, A. Boutejdar, M. Dehmas, A. Azrar, A. Omar, ACES J. 27 (10), (2012).

[5] L. Lim, J.S. Park, J.S. Lee, D. Ahn, S. Nam, IEEE Microwave Guided Wave Lett., 261 (2002). 